\title{
Identification of Bacterial Proteins Mediating the Interactions Between Pseudomonas putida UW4 and Brassica napus (Canola)
}

\author{
Zhenyu Cheng, Jin Duan, Youai Hao, Brendan J. McConkey, and Bernard R. Glick \\ Department of Biology, University of Waterloo, 200 University Avenue West, Waterloo, Ontario N2L 3G1, Canada
}

Submitted 16 December 2008. Accepted 7 February 2009.

\begin{abstract}
The influence of canola root exudates on the proteome of Pseudomonas putida UW4 and the mutant strain $P$. putida UW4/AcdS ${ }^{-}$, which lacks a functional 1-aminocyclopropane-1-carboxylate deaminase gene, was examined using two-dimensional difference in-gel electrophoresis. Seventytwo proteins with significantly altered expression levels in the presence of canola root exudates were identified by mass spectrometry. Many of these proteins are involved in nutrient transport and utilization, cell envelope synthesis, and transcriptional or translational regulation and, hence, may play important roles in plant-bacterial interactions. Four proteins showing large changes in expression in response to canola root exudates in both the wildtype and mutant strains of $P$. putida UW4 (i.e., outer membrane protein $F$, peptide deformylase, transcription regulator Fis family protein, and a previously uncharacterized protein) were both overexpressed and disrupted in $P$. putida UW4 in an effort to better understand their functions. Functional studies of these modified strains revealed significantly enhanced or inhibited plant-growthpromoting abilities compared with the wild-type $P$. putida UW4, in agreement with the suggested involvement of three of these four proteins in plant-bacterial interactions. The work reported here suggests strategies to both identify potential antibacterial agents and develop bacterial strains that might be useful adjuncts to agriculture. This approach may be an effective means of identifying key proteins mediating the interactions of bacteria with their rhizosphere environment.
\end{abstract}

Various components in plant exudates play important roles in plant-bacterial interactions (de Weert et al. 2002; Mark et al. 2005). Most previous studies of plant exudates have focused on their ability to be utilized by surrounding bacteria and, therefore, facilitate plant-bacterial interactions via bacterial chemotaxis, root colonization, and root growth stimulation (de Weert et al. 2002; Kamilova et al. 2006; Lugtenberg et al. 1999). For example, Mark and associates (2005) investigated global influences of plant exudates on bacterial gene expression and identified genes involved in rhizosphere colonization using microarrays, including some genes that had not been characterized previously. Most proteomic studies of plant-bacterial

Corresponding author: Z. Cheng; Telephone: +1-(519)-8884567 Extension 36686; Fax: 1-(519)-746-0614; E-mail: czhenyu@ sciborg.uwaterloo.ca

* The $\boldsymbol{e}$-Xtra logo stands for "electronic extra" and indicates that two supplemental tables and three supplemental figures are published online. interactions have focused on either symbiotic nitrogen fixing (Djordjevic et al. 2003; Natera et al. 2000) or phytopathogenic (Bouchart et al. 2007; Caldelari et al. 2006) bacterial strains. In spite of their potential agricultural and environmental importance (Lucy et al. 2004), proteomic studies of free-living plantgrowth-promoting bacteria have not been reported, in part because these organisms and their modes of action are less well characterized.

Pseudomonas putida UW4 is a plant-growth-promoting bacterium that contains the pyridoxal phosphate enzyme 1-aminocyclopropane-1-carboxylate (ACC) deaminase [EC 4.1.99.4], which catalyzes the deamination of ACC to produce $\alpha$-ketobutyrate and ammonia. ACC is the immediate precursor of the phytohormone ethylene, an important mediator of stress responses and plant growth and development (Abeles et al. 1992; Mattoo and Suttle 1991). A model describing how ACC deaminase-containing plant-growth-promoting bacteria modulate plant ethylene levels has been described (Glick et al. 1998). Briefly, along with other small molecules, a portion of the ACC in plants is exuded from plant roots or seed, and the bacteria attached to the surface of the seed or roots can take up some of this ACC and cleave it through the activity of ACC deaminase, thereby acting as a sink for ACC. Thus, ACC deaminase can limit inhibitory ethylene levels, often associated with various stresses, such as flooding, drought, pathogens, high salt, and the presence of organic and inorganic soil contaminants, while maintaining lower beneficial ethylene levels in plants (Stearns and Glick 2003). This model is consistent with a wide range of experimental data and is summarized in recent reviews (Glick 2005; Glick et al. 2007a and b; Lucy et al. 2004). The mutant strain $P$. putida $\mathrm{UW} / \mathrm{AcdS}^{-}$, lacking a functional acdS gene (encoding ACC deaminase), does not prevent ethylene inhibition of plant growth and, therefore, can only promote plant growth to a limited degree (Li et al. 2000). This limited plant-growth promotion is likely due to other mechanisms such as indole 3-acetic acid (IAA) synthesis (Li et al. 2000). Many beneficial bacteria synthesize IAA, predominantly by a tryptophan-dependent pathway, which can stimulate host root cell proliferation and elongation (Patten and Glick 1996, 2002). In addition to alleviating the inhibitory effects of ethylene, ACC deaminase-containing plant-growth-promoting bacteria also decrease the feedback inhibition of IAA signal transduction by ethylene (Glick et al. 2007a).

In the work reported here, the IAA and ACC levels in canola root exudates from control and bacteria-treated plants were compared to check the impacts of different bacterial strains on these levels. In order to identify bacterial proteins mediating interactions between the plant-growth-promoting bacterium $P$. putida UW4 and canola, protein expression profiles of bac- 
terial strains $P$. putida UW4 and $P$. putida $\mathrm{UW}$ /AcdS ${ }^{-}$following exposure to canola root exudates were investigated using proteomic tools.

\section{RESULTS}

Plant hormones in canola root exudates.

Canola seeds were treated with either $P$. putida UW4, $P$. putida $\mathrm{UW} / \mathrm{AcdS}^{-}$, or buffer as a control, and root exudates were collected 7 days after planting. Measurement of the IAA and ACC content of these exudates pooled from 300 plants (Fig. 1) revealed that treatment of plants with the wild-type strain dramatically increased the amount of IAA secreted by the plant whereas treatment of the $\mathrm{AcdS}^{-}$mutant strain only slightly increased IAA levels. In addition, treatment of plants with the wild-type but not the $\mathrm{AcdS}^{-}$mutant bacteria lowered the amount of ACC that was exuded.

\section{Comparative protein expression profiles.}

The protein expression profiles of $P$. putida UW4 and $P$. putida $\mathrm{UW} / \mathrm{AcdS}^{-}$in response to canola root exudates were analyzed and significant changes were observed in both samples. Out of a total number of 1,757 proteins detected on the analytical gels for P. putida UW4, the expression levels of 220 $(12.52 \%)$ proteins were significantly increased and 172 $(9.79 \%)$ proteins were significantly decreased $(P \leq 0.05$, expression ratio $\geq 1.5$ ). Results were comparable for the $P$. putida $\mathrm{UW} / \mathrm{AcdS}^{-}$strain, although a smaller number of differentially expressed proteins were detected. For the mutant strain, 1,670 proteins were detected, where expression levels of $164(9.82 \%)$ proteins were significantly increased and 115 $(6.89 \%)$ proteins were significantly decreased. Supplementary Figure 1 shows a representative analytical gel comparing protein expression of the wild-type $P$. putida UW4 exposed to canola root exudates (red) or buffer control (green).

\section{Mass spectrometric analyses.}

In total, 72 proteins with significantly different expression levels in the presence of the added plant exudates were successfully identified by mass spectrometry via matches to homologous proteins from other Pseudomonas strains (Supplementary Fig. 2) and divided into nine groups based on functional annotation from the Swiss-Prot database (Fig. 2; Table 1). In Figure 2, differential expression is visualized on a scale with red indicating upregulation and green indicating downregulation for identified proteins in the presence of canola root exudates in the wild-type and $\mathrm{AcdS}^{-}$strain, respectively. White boxes represent proteins whose expression was not significantly altered. Details of the mass spectrometric identification and differential expression are included in Table 1. Sixty-four of the protein expression changes were observed in the profiles of both strains. Proteins in groups I to $\mathrm{V}$ were significantly upregulated in the presence of canola root exudates in both the wild type and AcdS $^{-}$mutant. These proteins are involved in bacterial envelope synthesis and membrane transportation, as well as metabolism of nucleic acids, amino acids, and carbohydrates. ACC deaminase was significantly upregulated in the wild type, although at only a moderate level of 1.64-fold in the wild type. On the other hand, five transcriptional regulators in group VI were downregulated while one transcription repressor NmrA-like protein was upregulated. NmrA is a negative transcriptional regulator involved in controlling nitrogen metabolite repression (Andrianopoulos et al. 1998). Protein expression levels within group VII (protein synthesis, folding, and degradation) and group VIII (oxidoreductase) exhibited both increases and decreases. Finally, group IX includes a previously uncharacterized protein, a hypothetical protein $\mathrm{A}$, and cell division protein FtsA. From the 64 proteins whose expression changed significantly in both the wild type and AcdS mutant, 4 proteins were selected for additional analyses to confirm their involvement in plant-bacterial interaction.

\section{Root elongation promoting activities of the overexpressing and knockout strains.}

The first basis for the selection of the genes chosen for additional functional analyses is proteins that showed the greatest increase or decrease in expression ( $>7$ for upregulated proteins and $<-2$ for downregulated proteins). Another selection criterion is confidence in the mass spectromic identification (i.e., $>90$ and $80 \%$ for up- and downregulated proteins, respectively) in order to easily clone the genes from $P$. putida UW4 genome. There were four proteins that fulfilled these criteria and all of them were chosen for expression and mutagenesis studies. These proteins were one upregulated protein (outer membrane protein F) and three downregulated proteins (peptide deformylase, transcription regulator Fis family, and a previously uncharacterized protein). The genes $p d f$, fis, hyp, and ompF encoding peptide deformylase (Pdf), transcription regulator Fis family (Fis), uncharacterized protein (Hyp), and outer membrane protein $\mathrm{F}(\mathrm{OmpF})$, respectively, were amplified by polymerase chain reaction (PCR) using primers (Supplementary Table 2) designed based on analogues from other closely

\section{A ACC Quantification}

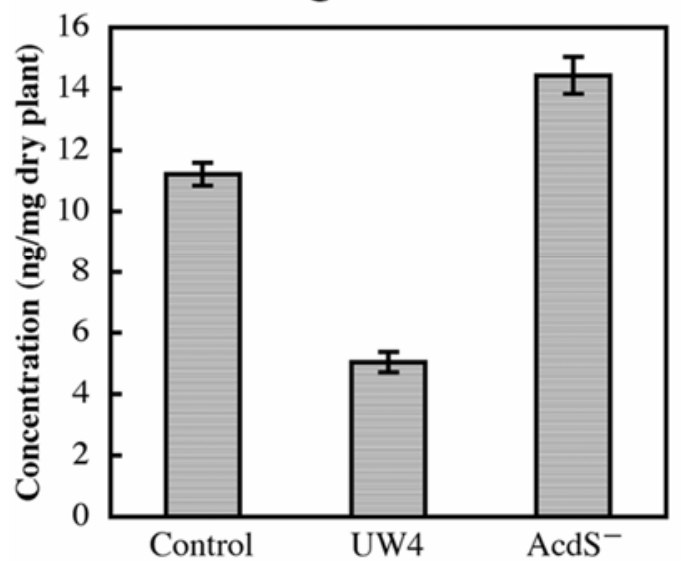

B

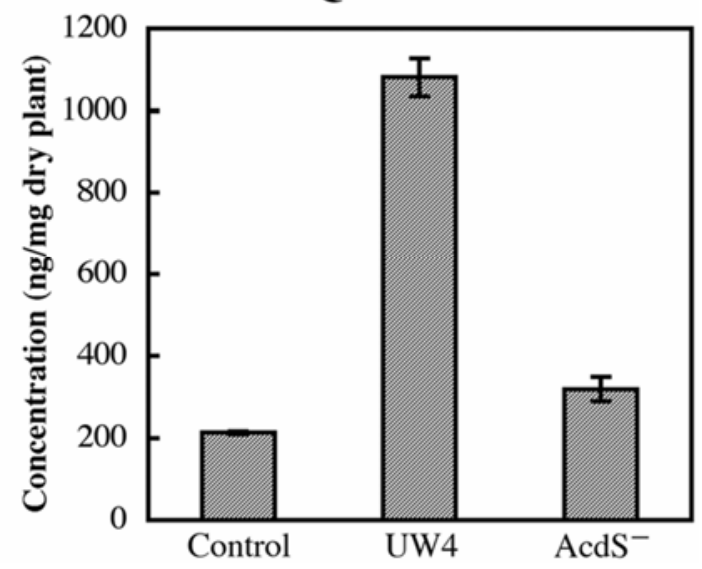

Fig. 1. A, 1-Aminocyclopropane-1-carboxylate (ACC) and B, indole 3-acetic acid (IAA) concentrations in the root exudates from control and treated plants. Exudates were pooled from 300 plants, and ACC and IAA concentrations measured in triplicate analytical high-performance liquid chromatography runs. 


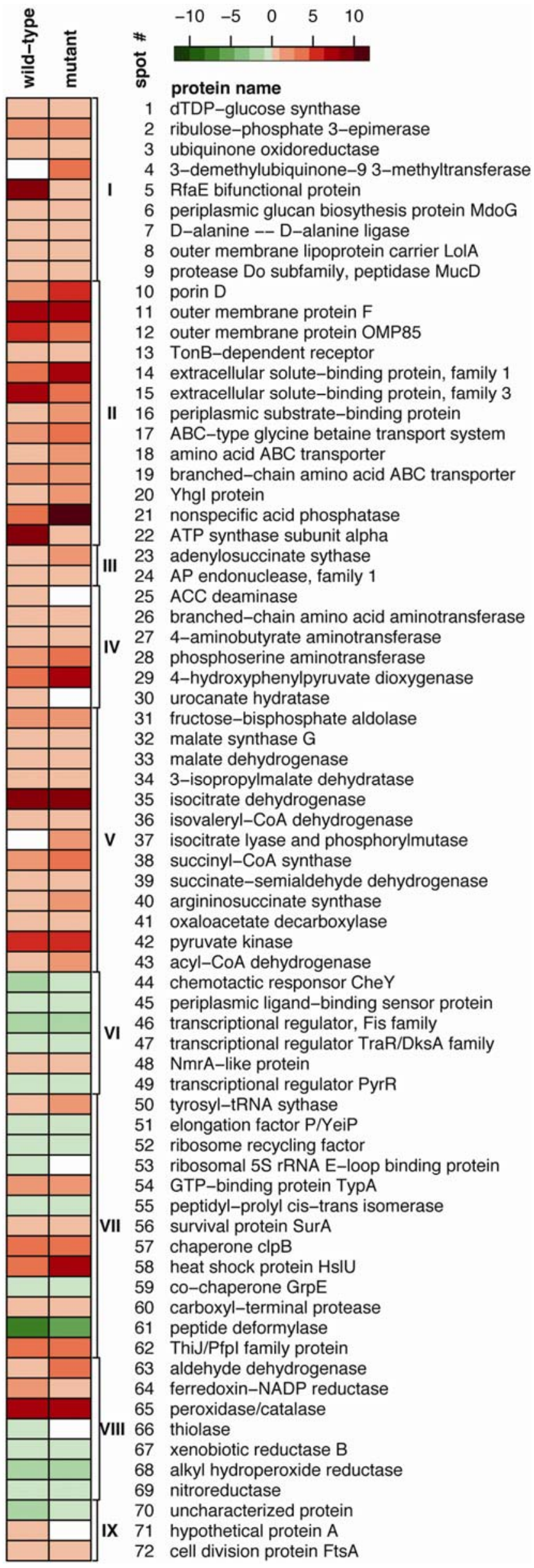

related Pseudomonas strains as described below. The coding sequences of the $p d f$, fis, hyp, and $o m p F$ genes were determined and deposited in the GenBank database under accession numbers EU514687-EU514690.

These four genes were cloned into the Pseudomonas-Escherichia shuttle expression vector pETP constructed (Supplementary Fig. 3A) for protein expression in P. putida UW4. The expression of the four $6 \times$ His-tagged recombinant proteins is shown in Figure 3A. In all instances, the expression of the cloned gene was confirmed by antibodies directed against the His-tag and from the calculated molecular mass of the proteins.

Diagnostic PCR for individual genes confirmed that the genes encoding three of these four abovementioned proteins were disrupted in the mutant strains $P$. putida $\mathrm{UW} / \mathrm{Fis}^{-}$, UW4/ $\mathrm{Hyp}^{-}$, and $\mathrm{UW} 4 / \mathrm{OmpF}^{-}$. In each case, the PCR products from the mutant strains were $1.5 \mathrm{kbp}$ longer than their alleles in the wild type, reflecting the insertion of the tetA gene into each of these genes (Fig. 3B). The P. putida UW4/Pdf ${ }^{-}$mutant was unable to survive, presumably because this mutation was lethal.

The plant-growth-promoting ability of the wild-type, AcdS mutant, four overexpressing, and three viable disruption mutant (nonexpressing) strains were tested in a canola root elongation assay (Fig. 4). This assay revealed that i) the $\mathrm{AcdS}^{-}$mutant demonstrated plant-growth-promoting ability to a significantly lesser extent $(77.8 \%)$ than the wild type, ii) the Fis protein overexpressing and knockout strains showed no significant difference compared with the wild type, iii) the strains overexpressing the Pdf and the OmpF proteins and the Hyp protein knockout strain promoted root length more than the wild type, and iv) the ompF protein knockout strain and the Hyp protein overexpresser lost their root-length-promoting activity. Moreover, overexpression of Hyp inhibited root growth relative to the untreated plants, suggesting that high levels of this protein were detrimental to plant growth.

\section{DISCUSSION}

Both ACC and IAA play important roles in the process of plant growth promotion by bacteria (Glick 1995; Patten and Glick 2002). In agreement with a previously proposed model (Glick et al. 1998) and published data showing a decrease in endogenous ACC levels when ACC deaminase is present (Penrose and Glick 2001), treatment of plants with $P$. putida UW4 decreased the exogenous ACC content to approximately half of the control level, whereas the mutant $P$. putida UW4/AcdS ${ }^{-}$, which doesn't have ACC deaminase, slightly increased the ACC concentration. On the other hand, there was a dramatic increase (4.5-fold) in the IAA level when plants were treated with $P$. putida UW4 and only a small increase (approximately $50 \%$ ) following treatment with the mutant $P$. putida $\mathrm{UW} / \mathrm{AcdS}^{-}$. Although plant endogenous IAA and ACC levels were not measured directly, the levels found in root exudates are expected to be highly correlated to the levels in root tissues. Because ACC deaminase decreases the negative feedback of ethylene on IAA signal transduction and synthesis (Glick et al. 2007a), it is not surprising that the wild-type $P$. putida UW4 can decrease the amount of ACC and, at the same time, increase the IAA level. In fact, some plant auxin-regulated genes were upregulated following treatment with an endophytic

Fig. 2. Differentially expressed protein profiles of Pseudomonas putida UW4 (left column) and P. putida $\mathrm{UW}^{2} / \mathrm{AcdS}^{-}$(right column) in response to root exudates. Fold protein expression changes are depicted according to the color scale at the top. Protein groups and names are listed to the right. 
plant-growth-promoting $P$. fluorescens strain that contains ACC deaminase (Wang et al. 2005). With the mutant strain $P$. putida $\mathrm{UW} / \mathrm{AcdS}^{-}$, the small observed increase in the IAA level may reflect exogenous IAA supplied by the bacterium without any change to the feedback inhibition of ethylene on IAA signal transduction and synthesis (Glick et al. 2007a; Li et al. 2000). The increased level of ACC following treatment of plants with the mutant is most likely a consequence of the IAA activation of ACC synthase. This data is consistent with the model describing how an ACC deaminase-containing bacterium modulates levels of both ethylene and IAA (Glick et al. $1998,2007 a)$. In this model, ethylene inhibition of IAA signal transduction limits the amount of ethylene that is produced by a plant as a consequence of the addition of exogenous IAA. IAA plays a dual role in promoting cell proliferation and elongation while at the same time stimulating the transcription of ACC synthase, one of the key steps in ethylene synthesis. In this way, ethylene may limit the amount of its own synthesis. By lowering the amount of ethylene, ACC deaminase relieves the ethylene repression of auxin response factor synthesis. This results in an increase in the IAA stimulation of growth without causing an increase in ethylene production.

The observation that mutant strain $P$. putida $\mathrm{UW}^{-} /$AcdS $^{-}$did not promote root elongation as well as the wild type is consistent with previous results ( $\mathrm{Li}$ et al. 2000). Although an ACC deaminase overexpressing $P$. putida UW4 strain was not constructed, a derivative of the endophytic plant-growth-promot-

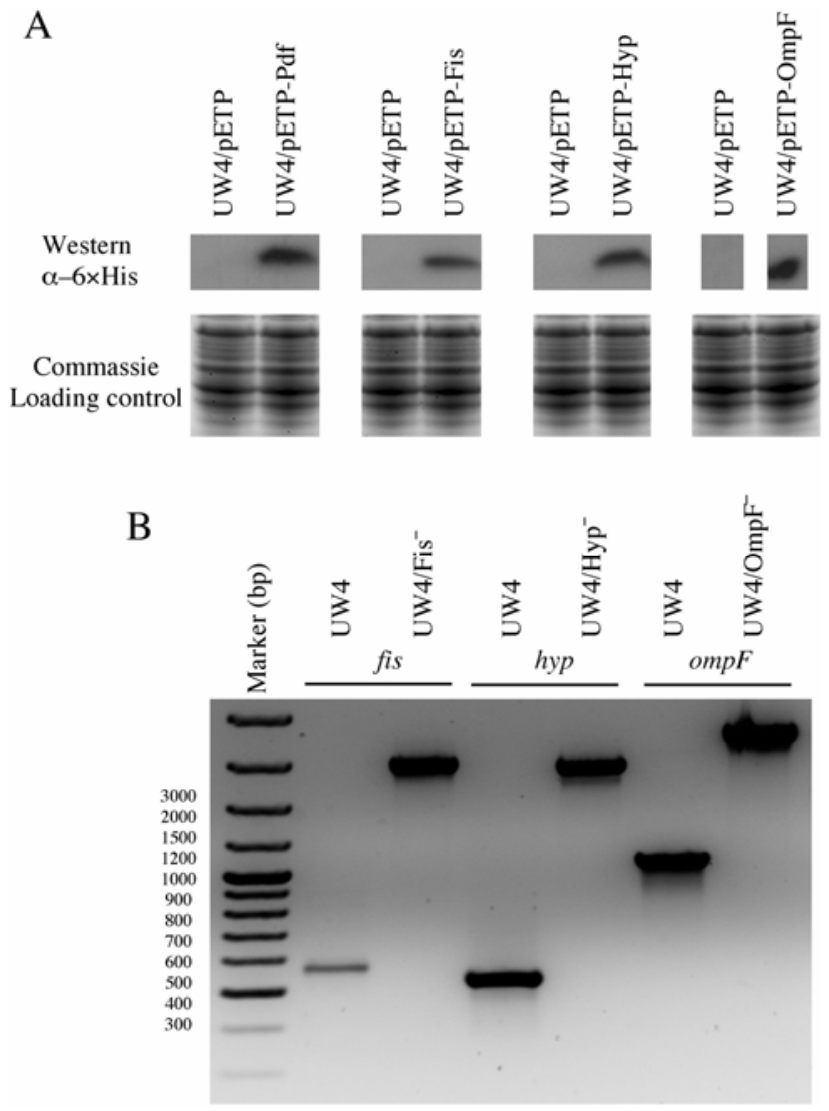

Fig. 3. A, Expression of the His-tagged recombinant proteins was confirmed by Western blotting. In the case of OmpF protein expression, twodimensional electrophoresis was performed to separate the expressed Histagged protein from a background band with similar molecular weight. B, Disruptions of target genes in the Pseudomonas putida UW4 genome were confirmed by diagnostic polymerase chain reaction (PCR) for individual genes. In each case, the PCR products from the mutant strains were 1.5 kbp longer than their alleles in the wild type, reflecting the insertion of the tetA gene into each of these genes. ing bacterium Burkholderia phytofirmans PsJN that overexpressed ACC deaminase compared to the wild type had a somewhat higher level of plant root elongation activity than the wild-type (Y. Sun, Z. Cheng, and B. R. Glick, unpublished data).

The effect of canola root exudates on protein expression was similar for wild-type $P$. putida UW4 and mutant $P$. putida UW4/AcdS $^{-}$(Fig. 5), with the majority of identified significant protein expression changes occurring in both the wild type and the AcdS $^{-}$mutant. This is not unexpected because the $P$. putida UW4 ACC deaminase is unlikely to be involved in bacterial perception and response to plant host signals, and it causes a noticeable difference only in plant growth. Nevertheless, we can draw the conclusion that the presence or absence of ACC deaminase has no significant impact on detected $P$. putida

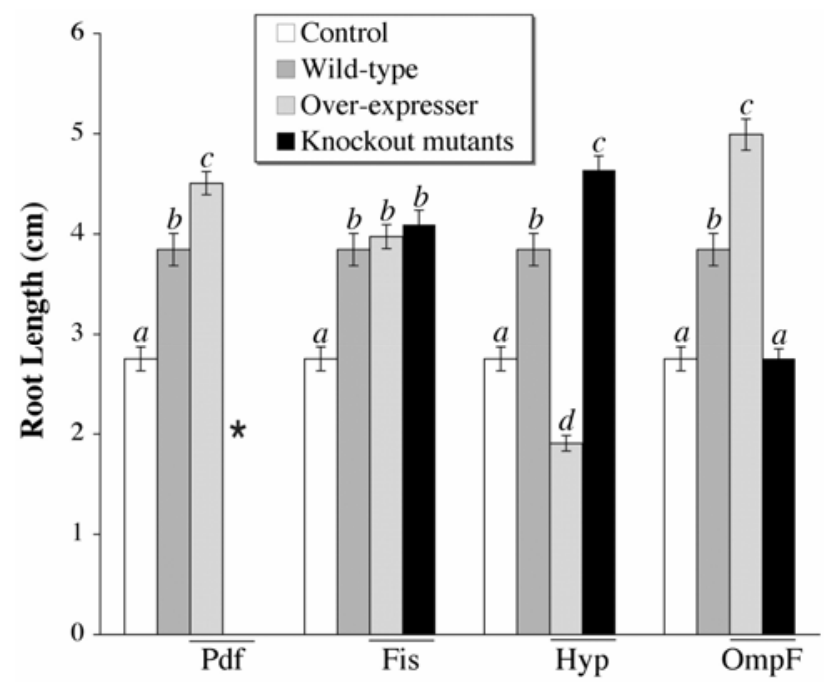

Fig. 4. Root length of 7-day-old canola seedlings. Letters represent results of analysis of variance of seedling root length, where statistical significance is indicated by a different letter. Error bars represent standard error of the mean with 67 to 70 plants per treatment. The asterisk indicates there is no root length data available for the UW4/Pdf-treated plants because the Pdf protein disrupted strain was not viable.

\section{Total Sample Plot}

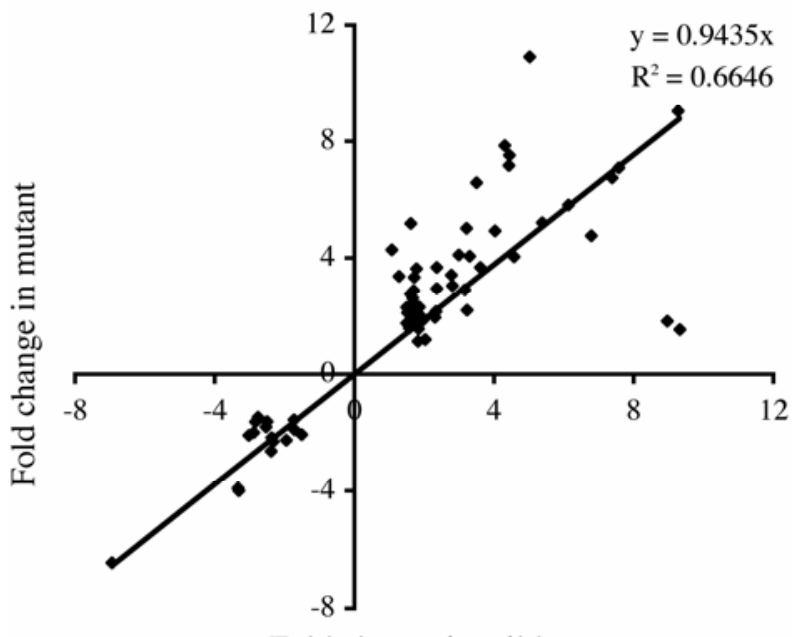

Fold change in wild-type

Fig. 5. Plot of protein expression changes in wild-type Pseudomonas putida UW4 in the presence of plant root exudates versus changes in the mutant P. putida $\mathrm{UW}_{4} / \mathrm{AcdS}^{-}$. Overall, similar changes in expression were observed in both treatments. 
UW4 gene expression on the exposure to canola root exudates; in other words, the wild-type $P$. putida UW4 and mutant strain $\mathrm{UW} / \mathrm{AcdS}^{-}$respond similarly to host signals in root exudates. On the other hand, when ACC deaminase minus mutants of $B$. phytofirmans PsJN were examined, their physiology was significantly changed compared with the wild type, indicating changes in expression levels of at least some proteins (Y. Sun, Z. Cheng, and B. R. Glick, unpublished data). These observations prompted us to investigate the proteomic profile of $P$. putida $\mathrm{UW} / \mathrm{AcdS}^{-}$along with the wild type. However, the differential in-gel electrophoresis (DIGE) analysis and especially the subsequent mass spectrometric analysis were both biased in that they largely examined highly abundant proteins. Thus, some less-abundant proteins that were differentially regulated in the wild-type $P$. putida $\mathrm{UW} 4$ and the $\mathrm{AcdS}^{-}$mutant were not readily detectable on the two-dimensional (2-D) gels or below the sensitivity level of the mass spectrometer.

Many of the proteins that are upregulated in response to canola root exudates are involved in the utilization of nutrients (Fig. 2; Table 1). This observation is consistent with a transcriptomic study of bacterial responses to plant root exudates
(Mark et al. 2005) and with the notion that the utilization of the major components in plant root exudates by pseudomonads is the nutritional basis for their colonization of host plant roots (Lugtenberg et al. 1999). Another group of proteins whose expression is increased participate in bacterial cell envelope synthesis, including exopolysaccharide and peptidoglycan biosynthesis and membrane lipoprotein localization, which are thought to be essential for bacterial root colonization, symbiosis, virulence, or even viability (Dekkers et al. 1998; Gao et al. 2001; Tanaka et al. 2001; Yorgey et al. 2001). In addition, a few other upregulated proteins, such as GTP-binding protein TypA, chaperone clpB, and a ThiJ/PfpI family protein, were all previously shown to be required during the interaction of bacteria with their plant hosts (Caldelari et al. 2006; Hughes et al. 2007; Kiss et al. 2004).

On the other hand, a protein involved in chemotaxis as a two-component response regulator, CheY, was downregulated by canola root exudates (Fig. 2; Table 1). This finding is in agreement with a previous observation (Mark et al. 2005) and with the idea that chemotaxis plays important roles in bacterial host selection and colonization (Mark et al. 2005) and re-

Table 1. Differentially expressed proteins identified by tandem mass spectrometry ${ }^{\mathrm{a}}$

\begin{tabular}{|c|c|c|c|c|c|c|c|c|c|}
\hline Spot, accession number & Protein & $\begin{array}{c}\text { MW } \\
(\mathbf{k D a})^{\mathbf{b}}\end{array}$ & $\mathbf{p} I^{\mathbf{b}}$ & Score $^{c}$ & $S^{d}$ & $\begin{array}{c}\text { WT } \\
\text { ratio }^{e}\end{array}$ & $\begin{array}{c}\text { WT } \\
P \text { value }\end{array}$ & $\begin{array}{l}\text { AcdS }^{-} \\
\text {ratio }^{\mathrm{e}}\end{array}$ & $\begin{array}{c}\text { AcdS }^{-} \\
P \text { value }\end{array}$ \\
\hline \multicolumn{10}{|l|}{ Cell envelope synthesis } \\
\hline 1, Q4KJY3_PSEF5 & dTDP-glucose synthase & 32.6 & 5.33 & 81.9 & 16.49 & 1.5 & 0.0017 & 2.29 & 0.011 \\
\hline 2, Q3K5U7_PSEPF & Eibulose-phosphate 3-epimerase & 24.1 & 4.95 & 94.21 & 40.62 & 2.81 & 0.00002 & 3.04 & 0.0081 \\
\hline 3, Q3K8P9_PSEPF & Ubiquinone oxidoreductase & 60.8 & 5.65 & 99 & 10 & 2.31 & 0.00002 & 1.95 & 0.019 \\
\hline 4, Q4K8M4_PSEF5 & 3-Semethylubiquinone-9 3-methyltransferase & 26.0 & 5.69 & 84.01 & 26.29 & 1.07 & 0.44 & 4.28 & 0.0058 \\
\hline 5, Q48P39_PSE14 & RfaE bifunctional protein & 50.2 & 5.54 & 87.68 & 10.13 & 8.96 & 0.00044 & 1.82 & 0.00089 \\
\hline 6, Q4KJM6_PSEF5 & Periplasmic glucan biosynthesis protein $\mathrm{MdoG}$ & 67.8 & 6.86 & 61.41 & 5.25 & 1.97 & 0.00002 & 1.86 & 0.0039 \\
\hline 7, Q3K746_PSEPF & D-alanine-D-alanine ligase & 34.4 & 5.02 & 93.49 & 14.2 & 1.66 & 0.0013 & 1.74 & 0.05 \\
\hline 8, Q3KA81_PSEPF & Outer membrane lipoprotein carrier LolA & 20.4 & 5.11 & 90.65 & 26.21 & 1.59 & 0.00058 & 2.05 & 0.032 \\
\hline 9, Q4KGQ4_PSEF5 & Protease Do subfamily, peptidase MucD & 50.7 & 6.20 & 64.45 & 11.55 & 1.64 & 0.029 & 1.77 & 0.04 \\
\hline \multicolumn{10}{|l|}{ Membrane transportation } \\
\hline 10, Q48FB5_PSE14 & Porin D & 47.0 & 4.94 & 60.66 & 4.32 & 3.5 & 0.00002 & 6.58 & 0.00009 \\
\hline 11, Q9X4L6_PSEFL & Outer membrane protein $\mathrm{F}$ & 36.6 & 4.68 & 90.82 & 13.08 & 7.57 & 0.0015 & 7.09 & 0.0055 \\
\hline 12, Q4KHG8_PSEF5 & Outer membrane protein OMP85 & 87.4 & 5.21 & 78.1 & 12.69 & 5.38 & 0.00022 & 5.21 & 0.0046 \\
\hline 13, Q9HT68_PSEAE & TonB-dependent receptor & 28.1 & 5.79 & 47.86 & 10.77 & 1.52 & 0.00076 & 2.11 & 0.0036 \\
\hline 14, Q3K503_PSEPF & Extracellular solute-binding protein, family 1 & 32.2 & 6.31 & 93.93 & 20.46 & 4.31 & 0.00096 & 7.85 & 0.00058 \\
\hline 15, Q3KHP0_PSEPF & Extracellular solute-binding protein, family 3 & 34.1 & 5.54 & 98.37 & 22.45 & 6.79 & 0.00006 & 4.76 & 0.00084 \\
\hline 16, Q3KFH7_PSEPF & Periplasmic substrate-binding protein & 35.6 & 5.72 & 94 & 10 & 1.61 & 0.015 & 2.76 & 0.0018 \\
\hline 17, Q3K5H9_PSEPF & ABC-type glycine betaine transport system & 32.0 & 5.85 & 99.24 & 28.25 & 2.99 & 0.00002 & 4.1 & 0.028 \\
\hline 18, Q4KH87_PSEF5 & Amino acid ABC transporter & 27.8 & 5.82 & 99 & 25.38 & 1.71 & 0.0032 & 3.33 & 0.0031 \\
\hline 19, Q88NR4_PSEPK & Branched-chain amino acid $\mathrm{ABC}$ transporter & 39.4 & 6.02 & 44.09 & 3.23 & 2.78 & 0.0013 & 3.41 & 0.00035 \\
\hline 20, Q4KAH1_PSEF5 & YhgI protein & 21.0 & 4.57 & 36.66 & 6.7 & 2.36 & 0.0031 & 3.67 & 0.019 \\
\hline 21, Q4KCT4_PSPF5 & Nonspecific acid phosphatase & 38.1 & 5.80 & 43.02 & 5.87 & 5.02 & 0.0013 & 10.91 & 0.00041 \\
\hline 22, Q87TT2_PSESM & ATP synthase subunit alpha & 55.3 & 5.46 & 100 & 38.33 & 9.32 & 0.011 & 1.53 & 0.0088 \\
\hline \multicolumn{10}{|l|}{ Nucleotide acid metabolism } \\
\hline 23, Q3KIY4_PSEPF & Adenylosuccinate sythase & 46.5 & 5.57 & 99.92 & 33.1 & 1.7 & 0.0031 & 2.87 & 0.0033 \\
\hline 24, Q4ZTK7_PSEU2 & AP endonuclease, family 1 & 31.1 & 5.89 & 74.92 & 8.15 & 1.78 & 0.017 & 1.82 & 0.0021 \\
\hline \multicolumn{10}{|l|}{ Amino acid metabolism } \\
\hline 25, Q4KK38_PSEF5 & ACC deaminase & 35.2 & 5.37 & 84.15 & 9.06 & 1.64 & 0.0012 & N/A & N/A \\
\hline 26, Q4KDP6_PSEF5 & Branched-chain amino acid aminotransferase & 36.9 & 6.19 & 69.37 & 6.78 & 1.7 & 0.043 & 1.73 & 0.017 \\
\hline 27, Q3KJX4_PSEPF & 4-Aminobutyrate aminotransferase & 44.8 & 5.91 & 99.83 & 31.76 & 1.72 & 0.0092 & 2.41 & 0.031 \\
\hline 28, Q4K8M8_PSPF5 & Phosphoserine aminotransferase & 40.0 & 5.04 & 41.82 & 2.75 & 3.21 & 0.002 & 5.02 & 0.0023 \\
\hline 29, P80064_PSEUJ & 4-Hydroxyphenylpyruvate dioxygenase & 40.1 & 5.23 & 99.65 & 31.37 & 4.44 & 0.00013 & 7.52 & 0.009 \\
\hline 30, Q4KJN8_PSEF5 & Urocanate hydratase & 61.3 & 5.79 & 74.19 & 6.61 & 1.82 & 0.0034 & 1.13 & 0.57 \\
\hline \multicolumn{10}{|l|}{ Carbohydrate metabolism } \\
\hline 31, Q3K5F5_PSESF & Fructose-bisphosphate aldolase & 38.5 & 5.48 & 94.52 & 24.86 & 3.16 & 0.014 & 2.9 & 0.0022 \\
\hline \multicolumn{10}{|c|}{ (continued on next page } \\
\hline
\end{tabular}

$\bar{a}$ Accession numbers refer to the top database match. Expression ratios and $P$ values were determined using differential in-gel electrophoresis analysis on triplicate bacterial cultures. Numbers in bold indicate proteins expression that was not significantly changed. Accession number of top database match from SwissProt Expasy database (Gasteiger et al. 2003).

${ }^{\mathrm{b}} \mathrm{MW}$ and $\mathrm{I}$ were calculated from amino acid sequence of the top database match using the Expasy Compute pI/MW tool (Gasteiger et al. 2003) and compared with gel location.

${ }^{c}$ PEAKS match score.

${ }^{\mathrm{d}}$ PEAKS sequence coverage.

e Wild type (WT) and mutant expression ratios relative to control, with upregulated proteins calculated as treated/control and downregulated proteins calculated as $-($ control/treated). N/A = not available. 
sponse to environmental stimuli (Nixon et al. 1986). The expression of a transcriptional regulator, a TraR/DksA family protein involved in quorum sensing, was also downregulated by canola root exudates. Previous studies have shown that the quorum-sensing circuitry that is operative in $P$. aeruginosa is essential for the expression of its virulence factors as well as for its biofilm formation when colonizing lungs of cystic fibrosis patients (Singh et al. 2000). In addition, expression of an essential protein in bacterial protein synthesis (peptide deformylase), a Fis family protein involved in DNA repair or modification, and a previously uncharacterized protein were also decreased more than twofold by canola root exudates.

Although some $P$. putida UW4 proteins that facilitate the establishment of host-bacterial interactions were upregulated in response to canola root exudates, some essential proteins were downregulated, which should inhibit bacterial growth. This downregulation could reflect the fact that, in the presence of sufficient resources, the bacterium no longer needs to synthesize proteins to the same extent as in the absence of nutrients. Again, this complexity in changing protein expression level in response to root exudates would appear to reflect a major shift in the physiology of bacteria that are associated with plant roots rather than free living.

The roles played by selected proteins that were differentially expressed in the presence of root exudates were investigated by overexpression or knockout of the corresponding genes. In the first instance, it was ascertained that the plant-growth-promoting activity of $P$. putida UW4 depends on the outer membrane protein $\mathrm{OmpF}$. The OmpF porin is a trimetric integral membrane protein which forms a nonspecific transport channel responsible for passive transport of small molecules, such as nutrients and waste products, across the outer membrane of gram-negative bacteria (Cowan et al. 1995). The OmpF protein is also thought to be involved in adhesion and invasion of the Crohn's disease-associated Escherichia coli LF82 (Rolhion et al. 2007). The fact that the OmpF protein overexpression and elimination in $P$. putida UW4 led to an increase and decrease, respectively, of its root elongation activity (Fig. 4) can be explained by two mechanisms. The plant-growth-promoting activity of $P$. putida UW4 relies on the transport of ACC from plant cells into attached bacterial cells, because ACC deaminase is localized and functions in the bacterial cytosol. Disrup-

Table 1. (continued from preceding page)

\begin{tabular}{|c|c|c|c|c|c|c|c|c|c|}
\hline Spot, accession number & Protein & $\underset{(\mathbf{k D a})^{\mathbf{b}}}{\mathrm{MW}}$ & $\mathbf{p} I^{\mathbf{b}}$ & Score $^{c}$ & $\mathbf{S C}^{\mathbf{d}}$ & $\begin{array}{l}\text { WT } \\
\text { ratio }^{\text {e }}\end{array}$ & $\begin{array}{c}\text { WT } \\
P \text { value }\end{array}$ & $\begin{array}{l}\text { AcdS }^{-} \\
\text {ratio }^{\mathrm{e}}\end{array}$ & $\begin{array}{l}\text { AcdS }^{-} \\
P \text { value }\end{array}$ \\
\hline \multicolumn{10}{|c|}{ Carbohydrate metabolism (Continued) } \\
\hline 32, O05137 PSEFL & Malate synthase $\mathrm{G}$ & 78.9 & 5.66 & 89.33 & 5.1 & 1.57 & 0.0031 & 1.58 & 0.00008 \\
\hline 33, Q1I6I3_9PSED & Malate dehydrogenase & 60.1 & 5.89 & 73.68 & 4.22 & 1.86 & 0.00006 & 2.3 & 0.0041 \\
\hline 34, Q3KF24 PSEPF & 3-Isopropylmalate dehydratase & 50.7 & 5.67 & 92.3 & 12.71 & 2.03 & 0.015 & 1.19 & 0.24 \\
\hline 35, Q4K9U5_PSEF5 & Isocitrate dehydrogenase & 45.4 & 5.27 & 99.97 & 27.75 & 9.27 & 0.0034 & 9.04 & 0.0098 \\
\hline 36, Q4K9P7_PSEF5 & Isovaleryl-CoA dehydrogenase & 42.4 & 5.74 & 60.43 & 6.46 & 1.69 & 0.0036 & 2.47 & 0.017 \\
\hline 37, Q3KFE9_PSEPF & Isocitrate lyase and phosphorylmutase & 32.0 & 5.46 & 95.24 & 20.95 & 1.28 & 0.057 & 3.37 & 0.0059 \\
\hline 38, Q883Z4_PSESM & Succinyl-CoA synthase & 41.2 & 5.70 & 98.07 & 28.35 & 3.3 & 0.0022 & 4.06 & 0.0003 \\
\hline 39, Q4KKA2 PSEF5 & Succinate-semialdehyde dehydrogenase & 51.6 & 5.75 & 96.18 & 14.37 & 1.77 & 0.00077 & 2.23 & 0.0048 \\
\hline 40, Q3K7K0_PSEPF & Argininosuccinate synthase & 45.4 & 5.38 & 77.93 & 7.41 & 1.67 & 0.0092 & 2.62 & 0.0022 \\
\hline 41, Q3K4C9_PSEPF & Oxaloacetate decarboxylase & 65.4 & 5.60 & 80 & 3 & 1.84 & 0.012 & 1.56 & 0.021 \\
\hline 42, Q3K7R9_PSEPF & Pyruvate kinase & 52.1 & 6.04 & 97.22 & 15.53 & 6.13 & 0.00052 & 5.82 & 0.00053 \\
\hline 43, Q3KC97_PSEPF & Acyl-CoA dehydrogenase & 40.9 & 5.25 & 95.43 & 20.46 & 1.78 & 0.01 & 3.63 & 0.0038 \\
\hline \multicolumn{10}{|l|}{ Transcription regulation } \\
\hline 44, Q51455_PSEAE & Chemotactic responsor $\mathrm{CheY}$ & 13.9 & 6.10 & 33.02 & 19.35 & -2.88 & 0.024 & -2 & 0.00062 \\
\hline 45, Q3K6E1_PSEPF & Periplasmic ligand-binding sensor protein & 26.6 & 4.34 & 85.76 & 8.73 & -2.83 & 0.00016 & -1.63 & 0.029 \\
\hline 46, Q3KI42_PSEPF & Transcriptional regulator, Fis family & 20.5 & 5.13 & 91.3 & 30.65 & -3.31 & 0.00006 & -4 & 0.014 \\
\hline 47, Q3K6R3_PSEPF & Transcriptional regulator TraR/DksA family & 16.9 & 5.21 & 62.4 & 20.41 & -2.38 & 0.00002 & -2.64 & 0.023 \\
\hline 48, Q3KDY8 PSEPF & NmrA-like protein & 26.8 & 5.15 & 75.2 & 13.55 & 2.34 & 0.01 & 2.15 & 0.016 \\
\hline 49, Q1I3U3_9PSED & Transcriptional regulator PyrR & 18.7 & 5.01 & 39.15 & 9.88 & -2.5 & 0.00038 & -1.62 & 0.044 \\
\hline \multicolumn{10}{|c|}{ Protein synthesis, folding and degradation } \\
\hline 50, Q4K517_PSEF5 & Tyrosyl-tRNA sythase & 44.2 & 5.49 & 90.7 & 10.78 & 2.36 & 0.025 & 2.94 & 0.003 \\
\hline 51, Q3K918_PSEPF & Elongation factor $\mathrm{P} / \mathrm{YeiP}$ & 21.0 & 4.72 & 99.43 & 36.51 & -1.73 & 0.0023 & -1.56 & 0.026 \\
\hline 52, Q886P0_PSESM & Ribosome recycling factor & 20.5 & 6.76 & 46.7 & 8.65 & -2.37 & 0.015 & -2.18 & 0.042 \\
\hline 53, Q88PX7_PSEPK & Ribosomal 5S rRNA E-loop binding protein & 21.1 & 5.72 & 92.2 & 10.14 & -2.76 & 0.00001 & -1.47 & 0.018 \\
\hline 54, Q3KJG5_PSEPF & GTP-binding protein TypA & 67.1 & 5.40 & 95.1 & 9.9 & 3.61 & 0.00004 & 3.67 & 0.0023 \\
\hline 55, Q4K5T2_PSEF5 & Peptidyl-prolyl cis-trans isomerase & 21.7 & 4.69 & 93.87 & 32.68 & -1.71 & 0.00002 & -1.9 & 0.0012 \\
\hline 56, Q4K4X7_PSEF5 & Survival protein SurA & 46.2 & 5.30 & 66.17 & 9.09 & 1.79 & 0.00005 & 1.67 & 0.033 \\
\hline 57, Q3K6N3_PSEPF & Chaperone clpB & 95.6 & 5.39 & 97.8 & 12.76 & 4.57 & 0.00005 & 4.04 & 0.00027 \\
\hline 58, Q3KJB6_PSEPF & Heat shock protein HslU & 50.0 & 5.76 & 92.5 & 9.89 & 4.43 & 0.0006 & 7.17 & 0.013 \\
\hline 59, Q4KIH2_PSEF5 & Co-chaperone GrpE & 20.8 & 4.65 & 92.2 & 35.64 & -1.95 & 0.0012 & -2.26 & 0.0045 \\
\hline 60, A5W7L4_PSEPU & Carboxyl-terminal protease & 75.0 & 6.10 & 95 & 3 & 1.87 & 0.00014 & 2.03 & 0.009 \\
\hline 61, Q3KKE5_PSEPF & Peptide deformylase & 19.4 & 5.17 & 82.91 & 23.81 & -6.94 & 0.00035 & -6.45 & 0.016 \\
\hline 62, Q4KGZ6_PSEF5 & ThiJ/PfpI family protein & 20.7 & 5.57 & 46.41 & 6.74 & 4.03 & 0.00017 & 4.93 & 0.00007 \\
\hline \multicolumn{10}{|l|}{ Oxidoreductase } \\
\hline 63, Q3K4N3_PSEPF & Aldehyde dehydrogenase & 53.2 & 5.37 & 96.81 & 13.88 & 1.62 & 0.0066 & 5.18 & 0.011 \\
\hline 64, Q48FA2_PSE14 & Ferredoxin-NADP reductase & 29.7 & 5.32 & 97.54 & 29.73 & 3.23 & 0.0034 & 2.2 & 0.0031 \\
\hline 65, Q3KE62_PSEPF & Peroxidase/catalase & 82.7 & 5.30 & 75.62 & 4.37 & 7.38 & 0.00004 & 6.75 & 0.026 \\
\hline 66, Q4ZY90_PSEU2 & Thiolase & 40.4 & 5.91 & 89.57 & 6.89 & -1.51 & 0.0053 & -2.07 & 0.09 \\
\hline 67, Q4KH19_PSEF5 & Xenobiotic reductase B & 37.4 & 5.53 & 96.43 & 16.33 & -2.53 & 0.00003 & -1.81 & 0.036 \\
\hline 68, Q3K7J6_PSEPF & Alkyl hydroperoxide reductase & 21.8 & 5.08 & 97.53 & 41 & -3.33 & 0.00008 & -3.92 & 0.004 \\
\hline 69, Q3KGH2_PSEPF & Nitroreductase & 22.0 & 5.79 & 85.9 & 20.3 & -2.32 & 0.0033 & -2.31 & 0.065 \\
\hline \multicolumn{10}{|l|}{ Others } \\
\hline 70, Q4KFS1_PSEF5 & Uncharacterized protein & 19.4 & 4.48 & 90.24 & 32.57 & -3.02 & 0.0073 & -2.1 & 0.049 \\
\hline 71, Q3K9Y9_PSEPF & Hypothetical protein A & 25.1 & 4.94 & 77.45 & 23.93 & 1.56 & 0.0028 & 2.29 & 0.11 \\
\hline 72, Q4ZNZ4_PSEU2 & Cell division protein FtsA & 44.6 & 5.26 & 91.12 & 11.24 & 1.5 & 0.0026 & 1.75 & 0.018 \\
\hline
\end{tabular}


tion or enrichment of the OmpF protein, which potentially transports ACC through the $P$. putida UW4 outer membrane, may directly affect its plant-growth-promoting ability. In this regard, changes to the expression of the OmpF protein are predicted to have little or no impact on the growth-promoting activity of the ACC deaminase minus mutant of strain UW4. Alternatively, the plant-growth-promoting activity of $P$. putida UW4, which is dependent on the direct physical binding of bacterial cells to plant surfaces, may also be dependent on the OmpF protein that may be involved in bacterial cell adhesion to the plant.

Second, based on the expression results, canola root exudates appear to contain a bacterial peptide deformylase inhibitory compound, which could potentially be employed as an antibacterial agent candidate. Peptide deformylase (Pdf) is involved in protein maturation after translation through its activity to remove the $\mathrm{N}$-formyl group of $\mathrm{N}$-formyl methionine. The Pdf protein is essential in eubacteria and absent in mammalian cells, making it an appealing target for the selection of novel antibiotics (Leeds and Dean 2006). The fact that the Pdf-protein-disrupted strain was not viable suggests that this protein is essential in bacterial cells (Fig. 4). Downregulation of the peptide deformylase in response to plant exudates (Fig. 2; Table 1) may reflect a plant mechanism to inhibit bacterial growth and limit colonization by bacterial pathogens. The strain overexpressing the Pdf protein promoted root length to a greater extent than the wild type, possibly by overcoming the inhibitory effects of a putative plant compound. Previously, exudates containing plant-derived antibacterial metabolites were shown to confer tissue-specific resistance to various bacterial pathogens (Bais et al. 2005). For example, actinonin, a naturally occurring bacterially encoded antibacterial agent, was previously identified as a Pdf protein inhibitor (Chen et al. 2000). Thus, the presence of a bacterial peptide deformylase inhibitory compound in root exudates may provide an opportunity to derive a potent and broadspectrum antibacterial agent.

The previously uncharacterized protein (Hyp) has been predicted to be a potential DNA binding protein (Marchler-Bauer et al. 2007). The observation that the Hyp protein may be involved in plant growth promotion has not been made previously. However, whether the Hyp protein is a DNA-binding protein possibly involved in gene transcriptional regulation is still conjecture at this point. Overexpression of the Hyp protein led to a growth inhibition of canola roots greater than that in the absence of bacteria (Fig. 4); therefore, it is possible that the Hyp protein has a role in regulation of genes related to virulence in $P$. putida UW4, causing detrimental effects on plant growth. Thus, the Hyp-protein-overexpressing strain not only abolished the plant-growth-promoting ability of $P$. putida UW4 but also may have transformed this bacterium into a deleterious organism that caused a decrease in root length compared with control plants (Fig. 4). Conversely, the Hyp protein knockout strain demonstrated an enhanced plantgrowth-promoting ability, probably due to elimination of deleterious effects that could have been attributed to the Hyp protein. Again, downregulation of the expression of the Hyp protein in response to plant root exudates (Fig. 2; Table 1) may be another plant self-protection strategy.

Previous workers have investigated some of the interactions between plant-growth-promoting bacteria and plants using other strategies based on transcriptomic characterization (RamosGonzalez et al. 2005; Verhagen et al. 2004; Wang et al. 2005). Here, proteomic profiling of the plant-growth-promoting bacterium $P$. putida UW4 in response to canola root exudates, followed by functional analyses, have suggested how some proteins may be involved in host-bacterial interactions. This approach should contribute to a better understanding of how both beneficial and pathogenic bacterial strains establish interactions with their hosts, because many of the proteins identified in this work were previously shown to be involved in pathogenic bacterial or fungal infections of plants and animals (Caldelari et al. 2006; Dumas-Gaudot et al. 2004; Hughes et al. 2007; Yorgey et al. 2001). Moreover, this work provides strategies to both identify potential antibacterial agents and develop bacterial strains that might be of significance to agricultural or environmental clean-up strategies.

\section{MATERIALS AND METHODS}

\section{Bacterial strains and growth.}

The microbial strains and plasmids used in this study are described in Supplementary Table 1. E. coli DH5 $\alpha$ (Hanahan 1983) was used as the host strain for the construction and maintenance of recombinant plasmids. E. coli strains were cultivated aerobically in Luria-Bertani broth or plates (Fisher Scientific Co., Ottawa, ON, Canada) at $37^{\circ} \mathrm{C}$. P. putida UW4 (Glick et al. 1995) and its mutant strains were cultivated aerobically in tryptic soy broth (TSB) or plates (Fisher Scientific Co.) at $30^{\circ} \mathrm{C}$. If required, the medium was supplemented with antibiotics at final concentrations of ampicillin at $100 \mu \mathrm{g} / \mathrm{ml}$, kanamycin at $30 \mu \mathrm{g} / \mathrm{ml}$, or tetracycline at $15 \mu \mathrm{g} / \mathrm{ml}$.

\section{Plant growth.}

Plant growth followed a previously described procedure with minor modifications (Penrose and Glick 2003). Briefly, seed of Brassica napus var. Westar were surface sterilized with $70 \%$ ethanol. Then, the sterilized seed were treated at room temperature for $1 \mathrm{~h}$ with induced (for either ACC deaminase activity or the proteins listed in Figure 3A) bacterial suspensions, diluted with sterile $0.03 \mathrm{M} \mathrm{MgSO}_{4}$ from an optical density at $600 \mathrm{~nm}\left(\mathrm{OD}_{600}\right)$ of approximately 2 to a final $\mathrm{OD}_{600}$ of 0.15 . Sterile $0.03 \mathrm{M} \mathrm{MgSO}_{4}$ solution-treated seed were used as a negative control. The treated and control seed (six per pouch) were planted in growth pouches (Cyg seed germination pouch; Mega International, St. Paul, MN, U.S.A.) containing $30 \mathrm{ml}$ of sterile Milli-Q water. The growth conditions, including time period, light intensity, and temperature, were all performed as exactly as described (Penrose and Glick 2003). For canola root exudates collection, the remaining water in all growth pouches was pooled and filtered through $0.2-\mu \mathrm{m}$ nitrocellulose filters, and the filtrates were stored at $-20^{\circ} \mathrm{C}$ in the dark. For plantgrowth-promotion assays, plant root length was measured following 7 days of growth at $20^{\circ} \mathrm{C}$ in a growth chamber with a light intensity of $200 \mu \mathrm{E}$ and a day-and-night regime of $12 \mathrm{~h}$ of light.

\section{Quantification of plant exudates components.}

The quantity of ACC in plant exudates were measured by the Waters AccQ·Tag Amino Acid Analysis Method (Waters Chromatography Inc., Mississauga, ON, Canada) The derivatization, separation, and detection processes were done by following the Waters AccQ.Fluor user guide. Amino acid derivatives (including ACC) were separated by a Hewlett Packard high-performance liquid chromatography (HPLC) system (1050 Series Quaternary Pump equipped with a high-efficiency $4 \mathrm{~m}$ Nova-Pak C18 column), and then detected by a Hewlett Packard 104a Programmable Fluorescence Detector at an excitation wavelength of $250 \mathrm{~nm}$ and an emission wavelength of $395 \mathrm{~nm}$. The flow rate was $1 \mathrm{ml} / \mathrm{min}$ and the gradient used was as described previously (Penrose and Glick 2001). The quantification of IAA was performed as described previously (Patten and Glick 2002), with modifications. Plant exudates were analyzed using a Perkin Elmer Series 4 HPLC equipped with an Allure 
reverse-phase C18 column ( $5 \mu \mathrm{m}$; 4.6 by $150 \mathrm{~mm}$ ) (Restek Inc., Rockville, ON, Canada). The elution buffer was acetonitrile and $50 \mathrm{mM} \mathrm{KH} \mathrm{PO}_{4}(\mathrm{pH} 3)(30 / 70)$ at a flow rate of 0.6 $\mathrm{ml} / \mathrm{min}$ and the eluates were detected by a Micromeritics 788 Dual Variable detector at $220 \mathrm{~nm}$.

\section{Proteomic profiling and DIGE analysis.}

Wild-type $P$. putida UW4 and mutant strain $P$. putida $\mathrm{UW} /$ AcdS $^{-}$were grown in $50 \mathrm{ml}$ of $2 \times$ DF minimal salts medium (Penrose and Glick 2003) supplemented with $50 \mathrm{ml}$ of collected plant root exudates or $50 \mathrm{ml}$ of sterile Milli-Q water to late-log phase for DIGE analysis.

The DIGE and the mass spectrometric analyses were done as follows. Briefly, proteins were extracted from bacterial cells by rotating the cells in ice-cold lysis buffer ( $2 \mathrm{M}$ thiourea, $7 \mathrm{M}$ urea, $4 \%$ CHAPS, $30 \mathrm{mM}$ Tris, $\mathrm{pH} 8.5 ; 5 \mathrm{ml} / \mathrm{g}$ of wet cells) containing $100 \mu \mathrm{l}$ of protease inhibitor cocktail (SigmaAldrich Canada Ltd., Oakville, ON, Canada) for $30 \mathrm{~min}$. The lysed cells were centrifuged at $150,000 \times g$ at $4^{\circ} \mathrm{C}$ for $90 \mathrm{~min}$ and the supernatant was saved at $-70^{\circ} \mathrm{C}$ as the whole cell extract. Protein samples extracted from differently treated bacterial cells were labeled with different Cye dyes (GE Healthcare, Mississauga, ON, Canada) and, subsequently, mixed together and separated on the same 2-D gel. All bacterial cultures and analytical gels used in DIGE analysis were done in triplicate. After 2-D electrophoresis, matching and statistical analyses of all protein spots were performed using the DeCyder V 6.0 software (GE Healthcare, Mississauga, ON, Canada). Proteins with a significant change in expression level were excised from preparative 2-D gels stained overnight with Bio-Safe Coomassie (Bio-Rad Laboratories, Mississauga, ON, Canada). The gel pieces containing proteins of interest were washed, destained, reduced, alkalized, dried, and then digested overnight with trypsin (Promega Corp., Madison, WI, U.S.A.). The tryptic peptides were recovered and cleaned using the C-18 ZipTip system (Millipore, Billerica, MA, U.S.A.) and eluted with $5 \mu \mathrm{l}$ of $50 \%$ acetonitrile containing $0.2 \%$ formic acid. The protonated peptides were analyzed using a Waters Micromass QTOF Ultima with nanospray injection as the sample delivery method. Proteins were identified using PEAKS software (v. 3.1; Bioinformatics Solutions Inc., Waterloo, ON, Canada) (Ma et al. 2003) against sequences in the Swiss-Prot database (Gasteiger et al. 2003).

\section{Expression and gene knockout in P. putida UW4.}

The Pseudomonas-Escherichia shuttle expression vector pETP was constructed by inserting the origin of replication (ori1600) from pUCP26 (West et al. 1994) into the SphI site of the expression vector pET30a(+) (Novagen, Hornby, ON, Canada). Using primers with either the original (PO) or the incorporated (PI) SphI site, the 1,557-bp fragment containing ori1600 was amplified from pUCP26 by PCR. Both the PCR fragment and the backbone vector, pET30a(+), were digested with $S p h \mathrm{I}$ and the fragment was inserted into pET30a(+). The resulting plasmid was designated as pETP.

The genes encoding the four selected proteins (Fig. 3A) were amplified by PCR using primers designed based on conserved up- and downstream regions in other Pseudomonas genomes ( $P$. fluorescence strains Pf-5 and PfO- 1 and $P$. putida strains KT2440 and F1). The PCR products were cloned into pGEM-T easy (Promega Corp.). The DNA sequences of these four genes were determined at the Biology Molecular Sequencing Facility, York University (Toronto). Four coding regions were cloned into pGEM-T easy using four sets of primers. The inserts, released by NotI digestion, were subcloned into the NotI site of pETP for expression in P. putida UW4. Plasmid constructs were resequenced to ensure that genes were inserted in the right reading frame and that no alternations to the DNA sequence had taken place. Plasmids were introduced into $P$. putida UW4 by electroporation as described (Smith and Iglewski 1989). The expression of the $6 \times$ His-tagged recombinant proteins was confirmed by Western blotting before these strains were used to treat canola seed in the root elongation growth pouch assay. 2-D Western was performed to separate the expressed $\mathrm{OmpF}$ protein from a large background band with the same molecular weight in the control sample (data not shown). The $6 \times$ His-tagged proteins were detected using a mouse monoclonal His-tag antibody (Novagen, Hornby, ON, Canada), and an HRP-conjugated anti-mouse immunoglobulin $\mathrm{G}$ secondary antibody (Sigma-Aldrich Canada Ltd.). The immune complexes were visualized by chemiluminescence using an ECL Plus Western blotting detection kit (GE Healthcare).

The mutant strains $P$. putida $\mathrm{UW} 4 / \mathrm{Fis}^{-}, \mathrm{UW} 4 / \mathrm{Hyp}^{-}$, and $\mathrm{UW} / \mathrm{OmpF}^{-}$were constructed by disrupting the fis, hyp, and $o m p F$ genes, respectively. A tetracycline resistance gene was inserted within the coding region of each of these genes by homologous recombination as described previously (Li et al. 2000). For example, the pBR322 EcoRI-Eco88I fragment containing the tetracycline resistance gene (tetA) (Peden 1983) was inserted into the $M s c I$ site within the fis coding sequence to make pGEM-Fis-tet. The pGEM-Fis-tet NotI fragment was then subcloned into the SmaI site of the pK19mobsacB, which facilitates gene disruption and allelic exchange by homologous recombination (Schafer et al. 1994). The resulting plasmid pRep-Fis was transformed into $P$. putida UW4 by electroporation (Smith and Iglewski 1989) and the transformants were selected on TSB plates containing tetracycline and sucrose. All mutant strains were tested for the disruption of the target genes by diagnostic PCR.

\section{ACKNOWLEDGMENTS}

We thank X. Ying for HPLC assistance and O. Woody for preparing figures. This work was supported by Natural Sciences and Engineering Research Council of Canada Discovery Grants to B. R. Glick and B. J. McConkey.

\section{LITERATURE CITED}

Abeles, F. B., Morgan, P. W., and Saltveit, M. E., Jr. 1992. Ethylene in Plant Biology. Academic Press, New York.

Andrianopoulos, A., Kourambas, S., Sharp, J. A., Davis, M. A., and Hynes, M. J. 1998. Characterization of the Aspergillus nidulans nmrA gene involved in nitrogen metabolite repression. J. Bacteriol. 180:1973-1977.

Bais, H. P., Prithiviraj, B., Jha, A. K., Ausubel, F. M., and Vivanco, J. M. 2005. Mediation of pathogen resistance by exudation of antimicrobials from roots. Nature 434:217-221.

Bouchart, F., Delangle, A., Lemoine, J., Bohin, J. P., and Lacroix, J. M. 2007. Proteomic analysis of a non-virulent mutant of the phytopathogenic bacterium Erwinia chrysanthemi deficient in osmoregulated periplasmic glucans: Change in protein expression is not restricted to the envelope, but affects general metabolism. Microbiology 153:760-767.

Caldelari, I., Mann, S., Crooks, C., and Palmer, T. 2006. The Tat pathway of the plant pathogen Pseudomonas syringae is required for optimal virulence. Mol. Plant-Microbe Interact. 19:200-212.

Chen, D. Z., Patel, D. V., Hackbarth, C. J., Wang, W., Dreyer, G., Young, D. C., Margolis, P. S., Wu, C., Ni, Z. J., Trias, J., White, R. J., and Yuan, Z. 2000. Actinonin, a naturally occurring antibacterial agent, is a potent deformylase inhibitor. Biochemistry 39:1256-1262.

Cowan, S. W., Garavito, R. M., Jansonius, J. N., Jenkins, J. A., Karlsson, R., Konig, N., Pai, E. F., Pauptit, R. A., Rizkallah, P. J., Rosenbusch, J. P., Rummel, G., and Schirmer, T. 1995. The structure of OmpF porin in a tetragonal crystal form. Structure 3:1041-1050.

Dekkers, L. C., van der Bij, A. J., Mulders, I. H., Phoelich, C. C., Wentwoord, R. A., Glandorf, D. C., Wijffelman, C. A., and Lugtenberg, B. J. 1998. Role of the O-antigen of lipopolysaccharide, and possible roles of growth rate and of NADH:ubiquinone oxidoreductase (nuo) in competitive tomato root-tip colonization by Pseudomonas fluorescens WCS365. Mol. Plant-Microbe Interact. 11:763-771. 
de Weert, S., Vermeiren, H., Mulders, I. H., Kuiper, I., Hendrickx, N., Bloemberg, G. V., Vanderleyden, J., De Mot, R., and Lugtenberg, B. J. 2002. Flagella-driven chemotaxis towards exudate components is an important trait for tomato root colonization by Pseudomonas fluorescens. Mol. Plant-Microbe Interact. 15:1173-1180.

Djordjevic, M. A., Chen, H. C., Natera, S., Van Noorden, G., Menzel, C., Taylor, S., Renard, C., Geiger, O., and Weiller, G. F. 2003. A global analysis of protein expression profiles in Sinorhizobium meliloti: Discovery of new genes for nodule occupancy and stress adaptation. Mol. Plant-Microbe Interact. 16:508-524.

Dumas-Gaudot, E., Valot, B., Bestel-Corre, G., Recorbet, G., St-Arnaud, M., Fontaine, B., Dieu, M., Raes, M., Saravanan, R. S., and Gianinazzi, S. 2004. Proteomics as a way to identify extra-radicular fungal proteins from Glomus intraradices-RiT-DNA carrot root mycorrhizas. FEMS (Fed. Eur. Microbiol. Soc.) Microbiol. Ecol. 48:401-411.

Gao, M., D’Haeze, W., De Rycke, R., Wolucka, B., and Holsters, M. 2001. Knockout of an azorhizobial dTDP-L-rhamnose synthase affects lipopolysaccharide and extracellular polysaccharide production and disables symbiosis with Sesbania rostrata. Mol. Plant-Microbe Interact. 14:857-866.

Gasteiger, E., Gattiker, A., Hoogland, C., Ivanyi, I., Appel, R. D., and Bairoch, A. 2003. ExPASy: The proteomics server for in-depth protein knowledge and analysis. Nucleic Acids Res. 31:3784-3788.

Glick, B. R. 1995. The enhancement of plant growth by free-living bacteria. Can. J. Microbiol. 41:109-117.

Glick, B. R. 2005. Modulation of plant ethylene levels by the bacterial enzyme ACC deaminase. FEMS (Fed. Eur. Microbiol. Soc.) Microbiol. Lett. 251:1-7.

Glick, B. R., Karaturovic, D., and Newell, P. 1995. A novel procedure for rapid isolation of plant growth-promoting rhizobacteria. Can. J. Microbiol. 41:533-536

Glick, B. R., Penrose, D. M., and Li, J. 1998. A model for the lowering of plant ethylene concentrations by plant growth-promoting bacteria. J. Theor. Biol. 190:63-68.

Glick, B. R., Cheng, Z., Czarny, J., and Duan, J. 2007a. Promotion of plant growth by ACC deaminase-producing soil bacteria. Eur. J. Plant Pathol. 119:329-339.

Glick, B. R., Todorovic, B., Czarny, J., Cheng, Z., Duan, J., and McConkey, B. 2007b. Promotion of plant growth by bacterial ACC deaminase. Crit. Rev. Plant Sci. 26:227-242.

Hanahan, D. 1983. Studies on transformation of Escherichia coli with plasmids. J. Mol. Biol. 166:557-580.

Hughes, V., Smith, S., Garcia-Sanchez, A., Sales, J., and Stevenson, K. 2007. Proteomic comparison of Mycobacterium avium subspecies paratuberculosis grown in vitro and isolated from clinical cases of ovine paratuberculosis. Microbiology 153:196-205.

Kamilova, F., Kravchenko, L. V., Shaposhnikov, A. I., Azarova, T., Makarova, N., and Lugtenberg, B. 2006. Organic acids, sugars, and Ltryptophane in exudates of vegetables growing on stonewool and their effects on activities of rhizosphere bacteria. Mol. Plant-Microbe Interact. 19:250-256

Kiss, E., Huguet, T., Poinsot, V., and Batut, J. 2004. The typA gene is required for stress adaptation as well as for symbiosis of Sinorhizobium meliloti 1021 with certain Medicago truncatula lines. Mol. PlantMicrobe Interact. 17:235-244.

Leeds, J. A., and Dean, C. R. 2006. Peptide deformylase as an antibacterial target: A critical assessment. Curr. Opin. Pharmacol. 6:445-452.

Li, J., Ovakim, D. H., Charles, T. C., and Glick, B. R. 2000. An ACC deaminase minus mutant of Enterobacter cloacae UW4 no longer promotes root elongation. Curr. Microbiol. 41:101-105.

Lucy, M., Reed, E., and Glick, B. R. 2004. Applications of free living plant growth-promoting rhizobacteria. Antonie Leeuwenhoek 86:1-25.

Lugtenberg, B. J., Kravchenko, L. V., and Simons, M. 1999. Tomato seed and root exudate sugars: Composition, utilization by Pseudomonas biocontrol strains and role in rhizosphere colonization. Environ. Microbiol. 1:439-446.

Ma, B., Zhang, K., Hendrie, C., Liang, C., Li, M., Doherty-Kirby, A., and Lajoie, G. 2003. PEAKS: Powerful software for peptide de novo sequencing by tandem mass spectrometry. Rapid Commun. Mass Spectrom. 17:2337-2342.

Marchler-Bauer, A., Anderson, J. B., Derbyshire, M. K., DeWeese-Scott, C., Gonzales, N. R., Gwadz, M., Hao, L., He, S., Hurwitz, D. I., Jackson, J. D., Ke, Z., Krylov, D., Lanczycki, C. J., Liebert, C. A., Liu, C., Lu, F., Lu,
S., Marchler, G. H., Mullokandov, M., Song, J. S., Thanki, N., Yamashita R. A., Yin, J. J., Zhang, D., and Bryant, S. H. 2007. CDD: A conserved domain database for interactive domain family analysis. Nucleic Acids Res. 35:D237-D240.

Mark, G. L., Dow, J. M., Kiely, P. D., Higgins, H., Haynes, J., Baysse, C., Abbas, A., Foley, T., Franks, A., Morrissey, J., and O'Gara, F. 2005 Transcriptome profiling of bacterial responses to root exudates identifies genes involved in microbe-plant interactions. Proc. Natl. Acad. Sci. U.S.A. 102:17454-17459.

Mattoo, A. K., and Suttle, J. C. 1991. The Plant Hormone Ethylene. CRC Press, Boca Raton, FL, U.S.A.

Natera, S. H., Guerreiro, N., and Djordjevic, M. A. 2000. Proteome analysis of differentially displayed proteins as a tool for the investigation of symbiosis. Mol. Plant-Microbe Interact. 13:995-1009.

Nixon, B. T., Ronson, C. W., and Ausubel, F. M. 1986. Two-component regulatory systems responsive to environmental stimuli share strongly conserved domains with the nitrogen assimilation regulatory genes $n \operatorname{tr} B$ and $n t r C$. Proc. Natl. Acad. Sci. U.S.A. 83:7850-7854.

Patten, C. L., and Glick, B. R. 1996. Bacterial biosynthesis of indole-3acetic acid. Can. J. Microbiol. 42:207-220.

Patten, C. L., and Glick, B. R. 2002. Role of Pseudomonas putida indoleacetic acid in development of the host plant root system. Appl. Environ. Microbiol. 68:3795-3801.

Peden, K. W. 1983. Revised sequence of the tetracycline-resistance gene of pBR322. Gene 22:277-280.

Penrose, D. M., and Glick, B. R. 2001. Levels of ACC and related compounds in exudate and extracts of canola seeds treated with ACC deaminase-containing plant growth-promoting bacteria. Can. J. Microbiol. 47:368-372.

Penrose, D. M., and Glick, B. R. 2003. Methods for isolating and characterizing ACC deaminase-containing plant growth-promoting rhizobacteria. Physiol. Plant 118:10-15.

Ramos-Gonzalez, M. I., Campos, M. J., and Ramos, J. L. 2005. Analysis of Pseudomonas putida KT2440 gene expression in the maize rhizosphere: In vivo expression technology capture and identification of root-activated promoters. J. Bacteriol. 187:4033-4041

Rolhion, N., Carvalho, F. A., and Darfeuille-Michaud, A. 2007. OmpC and the sigma(E) regulatory pathway are involved in adhesion and invasion of the Crohn's disease-associated Escherichia coli strain LF82. Mol. Microbiol. 63:1684-1700.

Schafer, A., Tauch, A., Jager, W., Kalinowski, J., Thierbach, G., and Puhler, A. 1994. Small mobilizable multi-purpose cloning vectors derived from the Escherichia coli plasmids pK18 and pK19: Selection of defined deletions in the chromosome of Corynebacterium glutamicum. Gene 145:69-73.

Singh, P. K., Schaefer, A. L., Parsek, M. R., Moninger, T. O., Welsh, M. J., and Greenberg, E. P. 2000. Quorum-sensing signals indicate that cystic fibrosis lungs are infected with bacterial biofilms. Nature 407:762-764.

Smith, A. W., and Iglewski, B. H. 1989. Transformation of Pseudomonas aeruginosa by electroporation. Nucleic Acids Res. 17:10509.

Stearns, J. C., and Glick, B. R. 2003. Transgenic plants with altered ethylene biosynthesis or perception. Biotechnol. Adv. 21:193-210.

Tanaka, K., Matsuyama, S. I., and Tokuda, H. 2001. Deletion of lolB, encoding an outer membrane lipoprotein, is lethal for Escherichia coli and causes accumulation of lipoprotein localization intermediates in the periplasm. J. Bacteriol. 183:6538-6542.

Verhagen, B. W., Glazebrook, J., Zhu, T., Chang, H. S., van Loon, L. C., and Pieterse, C. M. 2004. The transcriptome of rhizobacteria-induced systemic resistance in Arabidopsis. Mol. Plant-Microbe Interact. 17:895-908.

Wang, Y., Ohara, Y., Nakayashiki, H., Tosa, Y., and Mayama, S. 2005. Microarray analysis of the gene expression profile induced by the endophytic plant growth-promoting rhizobacteria, Pseudomonas fluorescens FPT9601-T5 in Arabidopsis. Mol. Plant-Microbe Interact. 18:385-396.

West, S. E., Schweizer, H. P., Dall, C., Sample, A. K., and RunyenJanecky, L. J. 1994. Construction of improved Escherichia-Pseudomonas shuttle vectors derived from pUC18/19 and sequence of the region required for their replication in Pseudomonas aeruginosa. Gene 148:81-86.

Yorgey, P., Rahme, L. G., Tan, M. W., and Ausubel, F. M. 2001. The roles of mucD and alginate in the virulence of Pseudomonas aeruginosa in plants, nematodes and mice. Mol. Microbiol. 41:1063-1076. 